\title{
O ethos do trabalho nas páginas de periódicos educacionais brasileiros: trabalhos manuais como signo da modernização pedagógica (1906 - 1934)
}

The work ethos in brazilian education journals: handworks as sign of pedagogical modernization (1906 - 1934)

El ethos del trabajo en las páginas de periódicos pedagógicos brasileños: trabajos manuales como signo de la modernización pedagógica (1906 - 1934)

\author{
Marcus Aurelio Taborda de Oliveira \\ Universidade Federal de Minas Gerais (Brasil) \\ https://orcid.org/0000-0002-6079-9710 \\ http://lattes.cnpq.br/0588758834590671 \\ marcustaborda@ufmg.br
}

\section{RESUMO}

O artigo discute a presença dos Trabalhos Manuais em duas revistas brasileiras: A Escola, publicada entre 1906 e 1921 no Estado do Paraná, e a Revista do Ensino, publicada a partir de 1925, no Estado de Minas Gerais, além de destacar o livro didático Trabalhos Manuais Escolares, de Manoel Penna, produzido em Minas Gerais, em 1934. Para além das preocupações com a formação de mão de obra para o trabalho fabril, a escola primária produziu nas primeiras décadas do século $\mathrm{XX}$ um conjunto de dispositivos curriculares para estimular a atividade do aluno, centrada na sua experiência. A relação entre educação escolar e trabalho pressupunha a mobilização dos sentidos para o desenvolvimento de sensibilidades apropriadas para um "novo mundo" que pretendia estimular a ação, o desenvolvimento da vontade e a capacidade de iniciativa como signos modernizadores da escola primária e da sociedade brasileira. Segundo a documentação mobilizada, tratava-se antes de fomentar o ethos do trabalho, mais do que visar qualquer tipo de preocupação com a formação de mão de obra, como bem demonstra o livro didático de Manoel Penna, a ser destacado ao longo do texto.

Palavras-chave: História do currículo; Educação do corpo; Educação dos sentidos e das sensibilidades; Educação e trabalho; Trabalhos manuais. 


\begin{abstract}
This study intends to discuss the Handworks presence in two pedagogical Brazilian journals: A Escola, published between 1906 and 1921 in Paraná state, and Revista do Ensino, published between 1925 and 1940, in Minas Gerais state, and the Manoel Penna's textbook Schoolar Handworks, published in Minas Gerais in 1934. Beyond preoccupations with workers formation for the factories, the primary school used different curricular strategies to stimulate students' activities. They were centered in students' experiences so that they could develop a disposition for action, according to the modern industrial world. Expressed in various ways between the end of 19th century and beginning of 20th century in virtually all Western world, the relation between education and work presupposed the mobilization of corporal senses for the development of appropriate sensibilities for a new world. That intention was to stimulate action, will development, and creative capacity, all modernizing signs of the primary school and of the Brazilian society, as show the Manoel Penna textbook highlighted in this article.
\end{abstract}

Keywords: Curriculum history; Body education; Education of senses and sensibilities; Education and work; Handworks.

\title{
RESUMEN
}

El artículo discute la presencia de los trabajos manuales en dos periódicos brasileños: $A$ Escola, publicada entre 1906 y 1921 en el Estado de Paraná, y la Revista de Ensino, publicada a partir de 1925, en el Estado de Minas Gerais, además de destacar el libro didáctico Trabalhos Manuais Escolares, de Manoel Penna, producido en Minas Gerais, el 1934. Además de las preocupaciones por la formación de mano de obra para el trabajo fabril, la escuela primaria produjo en las primeras décadas del siglo XX un conjunto de dispositivos curriculares para estimular la actividad del alumno, centrada en su experiencia. La relación entre educación escolar y trabajo presuponía la movilización de los sentidos para el desarrollo de sensibilidades apropiadas para un "nuevo mundo" que pretendía estimular la acción, el desarrollo de la voluntad y la capacidad de iniciativa como signos modernizadores de la escuela primaria y de la sociedad brasileña. Según la documentación movilizada, se trataba antes de fomentar el ethos del trabajo, más que visar cualquier tipo de preocupación con la formación de mano de obra, como bien demuestra el libro didáctico de Manoel Penna, a ser destacado a lo largo del texto.

Palavras-clave: Historia del currículum; Educación del cuerpo; Educación de los sentidos y de las sensibilidades; Educación y trabajo; Trabajos manuales. 


\section{Introdução}

No âmbito do projeto ${ }^{1}$ que venho coordenando nos últimos sete anos, buscamos focalizar um conjunto de iniciativas educativas, escolares ou não, que possam ser tratadas no âmbito de uma história dos sentidos e das sensibilidades, logo, da educação dos corpos. As relações entre educação e trabalho, tendo como uma das suas dimensões os trabalhos manuais na escola primária, apareciam na imprensa pedagógica das primeiras décadas do século XX ajuntadas a um vetor modernizador da educação, da escola e da sociedade brasileiras. Segundo nossa compreensão, eram vetores da produção de um novo tipo de sensibilidade. Cumpriam um papel fundamental naquele programa reformador a Educação Física, a Educação Artística, as Lições de Coisas, os jogos e esportes, além de rituais e rotinas que davam a ver a atividade dos alunos que, "trabalhando com as próprias mãos", produziam não só coisas úteis. Mas também disposições mentais sensíveis para o mundo industrial, considerado moderno, sempre enaltecendo a importância de os alunos terem, desde muito cedo, possibilidade de desenvolver amor pelo trabalho. O trabalho caracterizava-se, pois, como um forte veículo de educação geral no período aqui delimitado.

Tendo como suporte historiográfico a noção de economia moral, de Edward Thompson, além da discussão sobre trabalho, labor e vida ativa desenvolvida por Hannah Arendt, na primeira parte do texto discuto e problematizo a presença dos trabalhos manuais em duas revistas brasileiras, A Escola, publicada entre 1906 e 1921 no Estado do Paraná, e a Revista do Ensino, publicada a partir de 1925, no Estado de Minas Gerais, concluindo o percurso com a análise do livro didático Trabalhos Manuais Escolares, de Manoel Penna, publicado em 1934, ao qual dediquei a segunda parte do escrito. A revista paranaense foi acessada no acervo do Memorial Lysimaco Ferreira da Costa, em Curitiba. Já, a revista mineira está disponível no Centro de Documentação da Faculdade de Educação da UFMG, em Belo Horizonte. ${ }^{2}$ Ambas as publicações representaram o esforço de intelectuais e agentes públicos de estabelecer os parâmetros de reforma da escola brasileira, que gradativamente se inseria em um movimento de renovação pedagógica que teria seu ápice no Brasil, a partir da década de 1920, momento de amplas reformas sociais impulsionadas pela crescente urbanização e pelo processo de industrialização do país, que ajudaram a combater uma longa tradição de desprezo pelo trabalho manual. O livro de Penna ganha relevância por ser uma iniciativa editorial claramente voltada para o ensino, no qual o ethos do trabalho é enaltecido como signo dos novos tempos da formação da sociedade brasileira, não por acaso, a década de 1930.

Expressa de várias maneiras entre os finais do século XIX e o início do século XX em praticamente todo o mundo ocidental, a relação entre educação escolar e trabalho pressupunha a mobilização dos sentidos para o desenvolvimento de sensibilidades apropriadas para um "novo mundo" que pretendia estimular a ação, o desenvolvimento da vontade e a capacidade de iniciativa como signos modernizadores da escola primária. Entre os dispositivos curriculares que procuravam fomentar aquele ethos estavam os trabalhos manuais, ora presente como disciplina nos currículos escolares, ora como um tipo de atividade que perpassava diferentes disciplinas.

\footnotetext{
${ }^{1}$ A educação dos sentidos na história: o tempo livre como possibilidade de formação (entre os anos finais do séc. XIX e os anos iniciais do séc. XXI), desenvolvido na Universidade Federal de Minas Gerais. O projeto contou com apoio financeiro do CNPq sob n. 470687/2011-8 (Edital Universal), da CAPES, sob n. AUX-PEPNPD 2587/2011, e da FAPEMIG, sob n. APQ 00635/11 (Edital Universal).

${ }^{2} \mathrm{O}$ exemplar do livro de Manuel Penna aqui mobilizado foi gentilmente cedido pela professora Carla Simone Chamon, a quem agradeço pela confiança.
} 


\section{Qual trabalho? Uma educação para a vontade e a ação}

Tratar do tema do trabalho na realidade brasileira requer cuidados. Por um lado, porque sendo tardia entre nós a extinção do trabalho escravo (1888), toda a incipiente iniciativa industrial conhecida até aquele período tinha o trabalho forçado e o cativeiro como seus alicerces básicos. Por outro lado, o tardo desenvolvimento industrial de caráter moderno no Brasil estava centrado em tipos de produção pouco diversificados, muito limitados, não raro de caráter regional. Com isso, o que pode ser denominado de industrialização de caráter moderno entraria de forma significativa na cena societária brasileira apenas nas décadas iniciais do século $\mathrm{XX} \cdot{ }^{3}$ Esse tipo de consideração geral, inclusive, é desenvolvida por Manoel Penna, em 1934, para caracterizar o preconceito corrente na sociedade brasileira contra todo tipo de trabalho manual.

A consequência direta dessas condições foi a negação, por muito tempo, do trabalho como algo digno. De fato, as elites brasileiras até o século XIX viam o trabalho, em geral, e o trabalho manual, em particular, como expressão de uma condição subalterna. $\mathrm{O}$ trabalho era a danação dos escravos e necessidade de homens livres pobres, que sustentavam com a sua labuta a ociosidade das classes dominantes. Por isso não se pode falar, sobre aquele período da realidade brasileira, de um ethos de trabalho de caráter modernizador. O trabalho como signo da modernidade não havia ainda entrado na agenda política brasileira, o que ajuda a explicar a sua ausência nos planos de instrução pública que não tivessem um caráter profissional, a despeito de algumas iniciativas isoladas como aquelas de determinadas confissões religiosas ou de intelectuais como Rocha Pombo (Taborda de Oliveira, 2014). Ao contrário, até as últimas décadas do século XIX a ênfase da instrução pública recaia sobre o trabalho intelectual o qual, por sua vez, se dirigia à educação moral da infância e da juventude.

É com a gradativa denúncia dos males que o excesso de trabalho intelectual podia provocar nas crianças, os quais iam da fadiga - surmenage - aos possíveis danos no cérebro, que a ginástica, por exemplo, como trabalho com e do corpo, surge nas leis da instrução nas duas províncias no começo da década de 1880 (Puchta, 2015), seguindo um movimento geral de definição da sua obrigatoriedade no mundo ocidental. Aquela forma de trabalho do corpo, um pequeno signo modernizador, tinha como função precípua a compensação do esforço intelectual. Assim, não só a ginástica, mas também os jogos ganhariam lentamente o seu espaço nos programas escolares, não sem tensões. No período já circulavam no país obras de autores tais como Rousseau, Pestalozzi, Fröebel e Spencer, pensadores para os quais o trabalho corporal era uma condição básica no que se poderia chamar de educação integral. Mas a sua reverberação nos sistemas públicos de ensino ainda era tímida. Provavelmente foi uma combinação de fatores tais como o fim do regime escravocrata e o desenvolvimento do trabalho livre, a maciça chegada de imigrantes, as retóricas em torno da república com o consequente apelo ao direito à educação (Rocha, 1999), que permitiu que a instrução pública fosse objeto de preocupações de caráter modernizador, as quais concebiam a potência formativa do trabalho.

Como tem notado a historiografia sobre a escola brasileira, assiste-se, no país, a partir da última década do século XIX um conjunto de iniciativas de reforma da instrução pública. Entre vários aspectos daquele ciclo, um dos mais destacados se refere à tentativa de renovação dos currículos escolares (SOUZA, 1998, 1999). Os currículos, na sua expressão moderna, passam a

\footnotetext{
${ }^{3}$ Pode-se sustentar que a expansão da lavoura de café no sudeste do Brasil, no último quartil do século XIX, já estava marcada por um ciclo modernizador da indústria nacional. Da mesma maneira, algumas iniciativas da indústria de beneficiamento da erva mate e do couro, no sul. Os dois exemplos permitem observar como os estados de Minas Gerais e Paraná já contavam com um grau significativo de industrialização, além da exploração mineral, em Minas Gerais, ou da madeira, no Paraná. Mas a diversificação industrial era devedora dessas duas industrias com maior consolidação. Portanto, era muito restrita. Daí porque as retóricas que atrelavam o trabalho à industrialização, como processo de diversificação, e ambos à educação para um mundo novo, surgirem com mais força justamente nas décadas iniciais do século XX, quando, de fato, se assiste no Brasil um amplo e moderno processo de industrialização.
} 
considerar atividades relacionadas à educação física, à educação artística, aos trabalhos manuais, às Lições de Coisas, enfim, a um amplo leque de formas de educação do corpo, para além das tradicionais disciplinas nele presentes. Articulando-se de maneiras bastante diversas, essas atividades ajudavam a atestar o signo modernizador da escola brasileira, em conexão bastante íntima com processos similares ocorridos em outros países.

Naquele mesmo período podemos observar, ainda, uma profusão das iniciativas de produção de uma imprensa pedagógica. Ora por iniciativa das províncias e/ou estados, ora por iniciativa de diferentes confissões religiosas ou, ainda, de indivíduos ou grupos que se ocupavam do problema da instrução considerada pública, o fato é que a imprensa se tornaria um motor de divulgação de ideias, projetos, preceitos, críticas e prescrições sobre e para a marcha modernizadora do ensino público, inclusive difundindo realizações de outros países naquele domínio. ${ }^{4}$ Muitas das iniciativas modernizadoras aqui destacadas eram objeto corrente de preocupação dos editores e autores da revista A Escola (1906 - 1921) e da Revista do Ensino (1925 - 1934). A demarcação temporal aqui sugerida obedece aos propósitos deste artigo em relação aos trabalhos manuais nas escolas dos dois estados naquele que considero um período de renovação da educação primária no país. Deve-se destacar que, se a revista paranaense teve a sua série finalizada naquele interstício, já a sua congênere mineira é bastante longeva e foi publicada até a década de 1950.

A Escola foi publicada pelo Grêmio de Professores Públicos do Estado do Paraná, era subsidiada pelo Governo do Estado, e teve à sua frente intelectuais como Sebastião Paraná e Dario Velozzo. Alguns desses autores-diretores estavam entre os principais intelectuais do seu tempo no que se refere ao tema da renovação pedagógia. Já, a Revista do Ensino era uma iniciativa oficial do Estado de Minas Gerais, responsável por divulgar iniciativas inovadoras no âmbito da instrução pública no Estado. Tinha um caráter didático e muitas das suas matérias eram autoria dos professores escolares com um claro caráter pragmático, como é o caso de alguns textos assinados por Manoel Penna. Mas a despeito dos problemas metodológicos que dessas escolhas poderiam advir, meu propósito ao analisar os dois periódicos foi buscar compreender os sentidos dados à relação entre educação e trabalho naquelas duas realidades educativas que evocavam a renovação pedagógica, como circularam diferentes sentidos para a sua compreensão, sem pretender traçar uma análise comparada de tais contextos. Interessa-me, mais, compreender como o tema aparecia no debate pedagógico do período, considerado de grande impulso no que tange à educação popular, ou à educação das massas, e como ali se fincaram as bases de uma sensibilidade voltada para o trabalho. ${ }^{5}$

\footnotetext{
${ }^{4}$ Cabe, aqui, recordar que a instrução primária no Brasil era descentralizada. Isso implica reconhecer que cada província, no Império, ou cada unidade federativa, na República, dispunha sobre os seus sistemas de ensino. Por isso é sempre enganosa qualquer história que pretenda falar da educação no Brasil, na sua inteireza e homogeneidade, como frequentemente se assistiu. O tamanho, a diversidade e a complexidade do país, as grandes diferenças de desenvolvimento de cada região ou província, características demográficas, políticas e culturais, exigem cautela quando tentamos compreender o desenvolvimento da instrução pública. Logo, sem pretender estabelecer comparações, o que se buscou, aqui, foi compreender algumas conexões possíveis entre duas realidades distintas, a do Paraná e a de Minas Gerias, observando como na sua imprensa pedagógica circularam ideias e projetos sobre a modernização do ensino, tendo o trabalho manual como chave. Um esforço na direção de mapear diferenças e similaridades na constituição da escola pública brasileira em diferentes regiões tem sido coordenado pela professora Rosa Fatima de Souza (Souza et al, 2012).

${ }^{5}$ Não é ocioso lembrar que a instauração dos grupos escolares, considerados por alguns a expressão máxima do modelo escolar graduado, se deu em 1903, no Paraná, e em 1906, em Minas Gerais, dois entre os primeiros estados a reformar o ensino com base naquele modelo de organização. Além disso, na década de 20 os dois estados conheceriam reformas da instrução com a marca do movimento pela Escola Nova. Em 1921, no Paraná, e em 1927, em Minas Gerais. Por fim, mas não menos relevante, as duas primeiras Conferências Nacionais de Educação ocorreram nas capitais dos dois Estados. Em 1927, em Curitiba e em 1928 em Belo Horizonte. Antes, porém, ambos realizaram conferências educacionais dedicadas exclusivamente ao ensino primário e normal. 1926, em Curitiba, e 1927, em Belo Horizonte. A extensão do marco temporal do artigo a 1934 se deu justamente porque o livro de Manoel Penna condensa muito das discussões antes localizadas na imprensa
} 
Ligada diretamente à educação da vontade e à noção de vida ativa, a disposição para o trabalho vinha acompanhada de noções como progresso, melhora, avanço, dever, aptidão, ação, sempre com um caráter "positivado" que se opunha ao que era a instrução pública até aquele momento. Em relatório publicado na revista A Escola, a professora Julia Wanderley Petrich defendia que

Depois da educação física e intelectual se ocupará o professor da educação moral, porque é nesta mesma ordem que se observa o progresso humano.

No vastíssimo campo da moral, que tendo por objeto as ações humanas, estuda e dirige as faculdades que os presidem (sic!) - a sensibilidade e a vontade - o preceptor desempenhará preponderante papel aperfeiçoando o caráter e o coração de seus alunos, porque, como é sabido, o sentimento moral, unificando o ensino, eleva o mestre e dignifica a escola. Nas lições, nos passeios, a propósito de todas as ocorrências, cumpre ao mestre o imperioso dever de despertar-lhes a consciência moral, incutindolhes no animo as ideias do dever e do bem; os sentimentos da dignidade e da honra (Petrich, 1906, p. 19). ${ }^{6}$

A revista publicava, ainda, um Curso de Pedagogia que definia: "O professor conduz a criança à prática do dever, mantendo-lhe garantindo-lhe a liberdade de consciência" (Pereira, 1906: 123). Essa tônica na moral se via também nos "princípios relativos aos alunos": "Desejo de instruir$s e$ - a vontade é a base da educação moral". Finalizando, o Curso afirmava a educação moral como a principal dimensão educativa: "Moral - tem por base a experiência, o raciocínio e a vontade" (1906: 126). Os parâmetros para o desenvolvimento da vontade envolviam a exercitação do corpo, os jogos e os trabalhos manuais escolares. Segundo aquela perspectiva a "mais elevada moral" estaria representada em indivíduos propensos à ação. Além disso eram mobilizados os "novos conhecimentos" da ciência no que respeitava a pedagogia moderna. ${ }^{7}$

Temos nas palavras de algumas daquelas autoras, professoras, militantes, intelectuais, publicadas no Paraná, uma expressão do que a ação significaria para a construção de um pretendido novo mundo. Educar a vontade, significava a plena formação do homem além da sua simples instrução, como condição de construção de uma sociedade em bases modernas: civilizada, ativa, industriosa. Daí a importância da educação dos indivíduos. Não é demais lembrar que esse desejo de um indivíduo livre, esclarecido e dotado de vontade como condição da transformação do mundo, herdeiro da tradição iluminista, estava presente tanto nas utopias revolucionárias, quanto nas retóricas liberais-republicanas em países ainda fortemente marcados pela tradição monárquica, como o Brasil, no período aqui anisado. ${ }^{8}$

Um exemplo dessa ênfase aparece no relatório da já citada professora Julia Wanderley, responsável pela cadeira feminina do Grupo Escolar Xavier da Silva. Atestando seguir plenamente o que definia o Programa Escolar, a professora destacava a necessidade de uma formação geral das meninas, para a qual concorreria noções de trabalho.

periódica, motivo pelo qual o considero o ponto de chegada de um debate sobre a importância dos trabalhos manuais na escola.

${ }^{6}$ A trajetória de Julia Wanderley Petrich pode ser dimensionada no estudo de Araújo (2013).

${ }^{7}$ Um conjunto de reflexões de Alicia Moreau, feminista e socialista inglesa radicada na Argentina, foi traduzido de El Tiempo, de Buenos Aires, edição de 25 de setembro de 1906. A autora cita Froebel, Bebel, Le Bon e Pestalozzi, propondo a sequência evolutiva sensações, instrução, vontade, educação, como processo de afirmação de indivíduos livres, prontos para a ação no mundo. Ela também destaca a contribuição das ciências naturais contra o "palavrório e o cultivo da memória". Ver: Taborda de Oliveira (2017).

${ }^{8}$ Exploro com detalhes as retóricas sobre a educação da vontade, inclusive no registro de professores, em Taborda de Oliveira (2017). 
Como complemento do estudo de Agronomia, ministro-lhes também ligeiras noções de botânica, tendo sempre à vista exemplos d'apres nature; e quando tenho oportunidade lhes dou também algumas noções elementares de zoologia, anatomia e fisiologia por julgar que, conquanto essas matérias não façam parte do programa oficial, são, todavia de grande utilidade para os conhecimentos gerais que toda moça deve adquirir.

Reservo a quinta feira para a execução de prendas domésticas, de acordo com a determinação do Senhor Doutor Inspetor Escolar da Capital... (1906, p. 21-22).

Utilidade, prendas domésticas. A professora advogava a prática como um esforço de formação geral das alunas, sem qualquer ênfase que fizesse pensar em uma educação para a fábrica, mas ali estava expressa a atividade, o trabalho, como uma dimensão importante do processo de educação, da autonomia das alunas. Não por acaso eram comuns no período duras críticas contra o anterior modelo de escola que não permitia o movimento, a atividade, a iniciativa dos alunos. Aqui se pode falar de um ethos que faz pensar o trabalho como produção do mundo, no sentido proposto por Arendt (1958 [2014]), na sua crítica à tópica marxiana. Não é demais observar como, há apenas duas décadas da abolição da escravatura no país, a necessidade de atividade e ação aparece nas fontes sem qualquer referência ao trabalho de escravos negros e índios. Talvez porque o trabalho como ethos do mundo moderno de caráter industrial não devesse ter relação com as formas de trabalho que existiam sob o instituto da escravidão, que parecia negligenciar a noção de laboriosidade como algo a ser estimulado. Ainda é a professora Petrich a relatar:

150 objetos de diferentes formatos e diversos gêneros foram confeccionados pelas laboriosas alunas d'esta escola. D'estes, porem apenas 90 figuram no certâmen escolar que, graças aos louváveis esforços do benemérito Inspetor Escolar da Capital, teve lugar no dia 3 do corrente mês. Para aquela exposição deixei de enviar, pois, os objetos em duplicata, por julgar que nenhum interesse poderia despertar a exposição de trabalhos iguais (1906, p. 25).

Naquele momento os Trabalhos Manuais não eram uma disciplina na escola, nem mesmo estavam previstos no Programa. Mesmo assim já havia a disseminação da prática nas escolas públicas paranaenses, a ponto de os mesmos fazerem parte dos eventos de avaliação das escolas, na forma de exposição escolar, contando, inclusive, com a atribuição de conceitos. ${ }^{9}$ Não por acaso Ermelino de Leão reivindicava:

A escola da vida contra este outr'ora tão decantado templo da instrução, que poetas e utopistas nos apontavam como antidoto ao crime, vai garantindo aos povos que a criaram a supremacia na história contemporânea: ahi está a Norte-América surgida, ainda ontem, do seio das selvas para o grande concerto das nações dominadoras (Leão, 1908, p. 76).

A escola da vida tinha no homem industrioso, não necessariamente no operário especializado, o seu mais destacado vetor de modernização.

\footnotetext{
${ }^{9}$ O Arquivo Público Mineiro-APM, em Belo Horizonte, guarda inúmeras peças confeccionadas pelos alunos naquele estado nas primeiras décadas do século XX. Entre eles é possível encontrar desenhos, maquetes, bordados, costuras, brochuras etc. Esse acervo riquíssimo, parte da cultura material das escolas mineiras, ainda não foi cuidadosamente tratado pelos historiadores. No caso da exposição referida pela professora paranaense, ela ocorreu em 3 de dezembro de 1905.
} 


\section{Os Trabalhos Manuais como prática curricular.}

Si educar é preparar o homem para a vida, entendesse (sic!) que esta, por uma educação cada vez mais adequada, se está fazendo mais intensa, mais perfeita e mais digna de ser vida, fica fora de dúvida que não podem os métodos educativos deixar de possuir uma finalidade essencialmente utilitária (Santos, $\mathrm{n}^{\circ}$ 4, 1925, p. 81).

Assim anunciava o Editorial do quarto número da Revista de Ensino de Minas Gerais, de 1925. Desde os seus primeiros números o periódico mineiro dava grande destaque à relação entre trabalho e educação, sempre reivindicando a utilidade da segunda para a organização do mundo novo que se vislumbrava. Se, por um lado, "A educação, pois, não pode ser exclusivamente utilitária" (Santos, 1925, p. 81), por outro uma educação abstrata, beletrista e sem sentido prático de nada serviria para o país. No seu editorial Santos fazia questão de mencionar os Estados Unidos e Horace Mann, entre outros autores, como exemplos de espíritos industriosos de sucesso.

Citando Ferdinand Buisson, a revista já no seu primeiro número, pergunta: "Deve existir ligações entre o ensino profissional e o ensino primário propriamente? Quais?" (p. 4). A longa reposta percorrida em duas páginas da revista parte de um contraponto significativo. Tomado o ensino profissional na sua "acepção lata", a reposta seria negativa. Simplesmente porque ensino profissional estaria relacionado a algum grau de preparação técnica visando a atuação especializada. O autor oferece como exemplo as escolas de medicina e direito. Porém, tomada em sua acepção estrita “.... a elucidação da presente tese dependerá da maior ou menor extensão que tenha aquele ensino nos estabelecimentos primários propriamente ditos. Assim, se a extensão dada for tal que o estado converta o educando num operário ou num artificie - subsistirá a negativa, porque não é essa a missão exclusiva, ou primordial do ensino primário... Porém, se o ensino profissional for ministrado de forma tal que seja antes um ensino meramente manual, educador dos sentidos, encaminhador das faculdades motoras, iniciador da dexteridade (sic!) e da motilização (sic!), apenas preparatório do ensino profissional que se ministrará em outras escolas adrede organizadas... então impõe-se a afirmativa: devem existir ligações entre o ensino profissional, considerado como meramente manual, e o ensino primário propriamente dito". (GOES, 1925, p. 5, grifo meu).

Desteridade e motilidade, duas expressões que evidenciam a atividade como elemento fundamental das práticas educativas escolares. Os Trabalhos Manuais seriam, pois, um seguro caminho para a plena formação dos alunos, com diferenças conforme os sexos. Formação que poderia, inclusive, preparar os futuros operários, mas que a isso não se reduzia. Mas na sequência do seu texto, Carlos Goes relacionava um conjunto de argumentos de $\mathrm{A}$ a $\mathrm{Z}$ a favor dos trabalhos manuais nas escolas. Entre os argumentos defendia que "o ensino primário propõe, antes de tudo, a educação geral das faculdades da criança"; o trabalho manual representaria o equilibro entre o "ser" físico e o ser intelectual; exercitaria as três faculdades máximas da atividade: atenção, percepção e intuição; disciplinaria o aluno para ter método e paciência; desenvolveria o senso estético e a vontade; fomentaria "as forças geratrizes das riquezas sociais", entre tantos outros pontos. Remata o autor lembrando que "segundo Sundberg, o trabalho manual pedagógico, habilitando os olhos a ver, as mãos a trabalhar, e contribuindo para o desenvolvimento físico e moral dos alunos, consiste um contrapeso à pedagogia puramente livresca" (Goes, 1925 , p. 5). Tudo isso para desenvolver uma "aptidão geral às diversas circunstâncias da vida prática”, constantemente evocada naqueles tempos de renovação. 
Lembrando Rousseau, o autor destacava que "o trabalho manual é a ocupação que mais aproxima o homem do estado da natureza". Mas na sua galeria são feitas referências a Diderot, Comenius, Rabelais, Saint Just, bem como o elogio da revolução francesa e da lei de 28 de março de 1882, na França, que instituiu a obrigatoriedade da instrução primária, já com a presença dos Trabalhos Manuais (com e sem utensílios) nas escolas. Também aqui, como nos textos publicados ao longo das duas décadas anteriores em A Escola, no Paraná, a retórica modernizadora que tinha os Trabalhos Manuais como um vetor privilegiado não se eximia de recorrer aos exemplos da Europa ou dos Estados Unidos. Na conclusão do seu longo escrito, Goes lembrava que os trabalhos manuais exigiam uma acurada capacidade de observação da natureza, podendo estar dispersos nas disciplinas de Desenho, Aritmética e nas Lições de Coisas, embora o autor observasse que essa não seria propriamente uma disciplina, mas um processo de ensino relacionado ao método intuitivo (p. 6).

Ainda no mesmo ano, mas no número 5 da Revista do Ensino observamos outros trabalhos relacionados ao tema, tais como "O estudo do desenho e a cultura dos sentidos estheticos", do Prof. Anibal Mattos - p. 83; "A memoria visual e auditiva", sem autoria - pp. 86; além de outro longo trabalho intitulado "Finalidade do trabalho manual para mulheres", de Aprigio de Almeida Gonzaga - pp. 117-140. Este autor teceria profundas críticas à importação de "modelos estrangeiros" para a educação brasileira, mostrando um pouco da polifonia presente no periódico.

A escola que não atende à natureza e ao caráter da raça que educa e instrui; a escola que emprega sistemas de ensino de outros povos, sem consultar as diosincrasias (sic!) do seu meio, as particularidades do caráter dos seus educandos, submetendo-os a mesma razoria (sic!), não presta um grande serviço à sua pátria, porque afoga a porção mais bela da alma humana: a expansão da personalidade. Façamos a escola brasileira no meio brasileiro (Almeida Gonzaga, 1925, p. 117).

Para o autor a educação da mulher deveria estar voltada para a função da "mãe de família, dona de casa" (Almeida Gonzaga, 1925, p. 117). Por isso ele fazia críticas contundentes à renovação em marcha. Sobre o objeto da escola, asseverava:

A finalidade do ensino profissional de artes e ofícios para a mulher não me parece bem orientada. A escola profissional dever-seia chamar "Escola de Educação doméstica e profissional". Eu quero a escola que prepare a dona de casa, dando-lhe uma profissão, e não a escola que forme operarias, em detrimento da sua missão social. Deixemos de parte toda essa questão de direitos, reivindicações e feminismos. Atendamos a natureza, que, na organização e diferenciação orgânica de cada um, estabeleceu as funções e as adaptações à vida (Almeida Gonzaga, 1925, p. 117).

Para o autor o papel da mulher era inequívoco, e para ela deveria ser organizada uma "escola doméstica":

A escola domestica profissional deve organizar-se de modo que a mulher se baste a si mesma e seja um elemento da evolução humana. Para isso, a mulher tem deveres e direitos: educar-se, dirigir o lar e trabalhar, como diz uma grande educadora. Educando-se, adquire as suas qualidades precisas para armar o seu espirito e fazer-se cada vez melhor; elevar-se e compreender a sua 
alta função social, as suas responsabilidades no magno problema da educação dos filhos, na orientação do esposo, no governo do lar, e na preparação dos cidadãos da pátria. Dirigindo o lar, mãe de família, ela está no seu verdadeiro papel, no seu trono de majestade, onde, plasmando o caráter dos filhos, formando-lhes a alma, contendo e aconselhando o esposo, é causa de grandeza, de valor da sua pátria" (Almeida Gonzaga, 1925, p. 118).

O autor considerava que "Hoje, como diz Kroptkine, homens e mulheres, todos devem trabalhar e ganhar a vida com o seu próprio esforço. No mundo não há mais lugar para os inúteis" (Almeida Gonzaga, 1925, p. 118). O fim da escola para as mulheres também deveria ter um caráter utilitário que se destinaria muito mais ao desenvolvimento de um tipo específico de sensibilidade, que propriamente à formação de mão de obra, embora esta não fosse negada:

Mas, repito, não deve a escola domestica cuidar só disso: educar a dona de casa. É preciso dar-lhe uma profissão, para que, quando solteira, possa a mulher viver do seu trabalho e cooperar também, ao lado do homem; e, indo às fabricas, aos escritórios, às profissões liberais, concorrer para a riqueza e o progresso do país. Logo, organizada a escola doméstica, sem fazer operários, mas visando a educação harmônica da mulher, focalizemos dentre todas as matérias a economia doméstica, que podemos dividir em 3 partes: a cozinha, a higiene infantil e a casa (Grifo meu, Almeida Gonzaga, 1925, p.118-119).

Também os homens mereciam um tópico à parte nas considerações de Almeida Gonzaga. O segundo item do seu trabalho, intitulado Finalidade do trabalho manual para homens se refere ao Sloyd como uma "ginastica cerebral". Ali defende que "O trabalho manual é o centro da vida escolar e todas as demais disciplinas lhe gravitam em torno" (Almeida Gonzaga, 1925, p. 126). Lembrando que o trabalho foi a condenação imposta ao homem pelo seu "crime", comentava que a natureza humana necessita do trabalho para a conservação da espécie. Assim, "Na educação do espirito e do corpo, pelo exercício manual e intelectual, combinados, este apoiado naquele, procuramos fazer na escola a evolução do próprio ser, a nova educação, que é o centro da futura democracia" (Almeida Gonzaga, 1925, p. 126).

Entre tantas outras importantes finalidades, o trabalho manual cumpriria um papel primordial na formação cívica dos jovens, conforme texto transcrito da Revista de Ensino de São Paulo, o que só confirma a circulação de ideias sobre o tema, no período, não apenas no Brasil. Mencionando o reformador bávaro Georg Kerchensteiner e a sua pedagogia, baseada na escola de trabalho, assim como mais uma vez o Sloyd sueco, remata afirmando que "Esta educação [...] acarreta a eliminação ou correção das aberrações inatas, físicas e moraes [...]" (Almeida Gonzaga, 1925, p. 182). ${ }^{10}$ Entre as cinco ações destacadas pelo autor para que fosse respeitado o espírito prático do Estado e o método educativo da escola pública, enumerava os esportes, inclusive o futebol, as excursões, bibliotecas e trabalhos manuais. A quinta ação era o pingue-pongue... (Gonzaga, 1925, p. 183).

A força do tema era tão grande nas páginas da revista, no período, que em 1926, no seu número 11, foi publicado um Canto do trabalho, poema de Anna Amelia de Queiroz Mendonça:

\footnotetext{
${ }^{10}$ Sobre a ênfase do trabalho nas concepções educativas de Georg Kerchensteiner ver Caruso (2005).
} 
Trabalho é gloria. Quem trabalha

Vive feliz, sereno e são.

No ferro em brasa o homem que malha

Busca a beleza e a perfeição.

Em boca ardente da fornalha

Engue-se um hino à criação. [...]

A vida é áspera batalha,

Em que a arma rude é o rode mão.

Bendito seja quem trabalha

Pela grandeza e a perfeição" (Mendonça, $R d E, \mathrm{n}^{\circ} 11,1926$, p. 52).

O ensino profissional também ganhava relevo no período, e esteve entre as teses apresentadas na I e na II Conferência Nacional de Educação em Curitiba e Belo Horizonte, respectivamente. Em 1927 a Revista do Ensino transcreve texto de autoria de José Rangel, no qual começava se esboçar um claro deslocamento dos trabalhos manuais percebidos como uma dimensão fundamental da formação geral das crianças - o que venho denominando de um ethos do trabalho -, para outra perspectiva na qual a escola, em tese, seria a responsável por uma preparação cuidadosa dos futuros trabalhadores (Rangel, 1927, n. 22, pp. 523-524).

Lembrando que 1927 foi o ano da reforma Francisco Campos em Minas Gerais, a qual instauraria no Estado alguns preceitos da Escola Nova, muitos artigos da revista se voltavam para a exploração dos fundamentos da escola ativa, sendo que novamente os Estados Unidos surgiam como modelo. Em "Orientação da escola ativa nos Estados Unidos", Gustavo Lessa abordou a sua origem, os seus princípios, a sua relação com a Lição de Coisas, as suas práticas. Conferiu destaque ao que chamou de treino do pensamento e da vontade, à necessidade de passar da retórica ou projeto à ação, e finalizou tratando da educação moral e da educação social (pp. 52-73).

Nesse ponto podemos nos deter e observar como, em aproximadamente duas décadas, os Trabalhos Manuais passam de um difuso conjunto de práticas nas escolas primárias, a um dos aspectos centrais da educação pública nos dois periódicos analisados. O manual didático de Manuel Penna pode ser considerado o ponto de culminância daquela ênfase.

\section{Um manual didático para os trabalhos manuais escolares.}

Já na apresentação do seu livro Manoel Penna afirmava que a obra nada tinha de original. ${ }^{11}$ Antes, se valia da consulta e recorria a vários autores para dimensionar o lugar dos

\footnotetext{
11 Manoel Penna dedica o livro "à memória do inolvidável tecnocrata João Pinheiro da Silva e de meus colendos professores Caetano de Azeredo Coutinho e João Diniz Barbosa”. O autor foi professor de Trabalhos Manuais no Grupo Escolar Barão do Rio Branco, de Belo Horizonte. No momento da publicação do seu manual era "Assistente Técnico Especializado do ensino estadual e professor do Curso de Desenho da Escola de Aprendizes Artificies de Minas Gerais". O exemplar consultado, no alto da sua primeira página registra a data de 04/05/1944, na qual foi dedicado a "D. Noemi” como lembrança, embora não se possa identificar pela assinatura o ofertante. Na parte inferior da mesma página foi registrado: "lembrança de D. Noemi. 10/06/1945 Eulália Maria de Almeida Grupo Escolar 'Bias Fortes' 2. Turno Barbacena”. Ou seja, 10 anos após a sua publicação, aparentemente o livro de Penna circulava entre os professores de Minas. Não posso afirmar com precisão quem era a "D. Noemi", duplamente citada. Mas pode ser a Dona Noemi Gontijo, professora que se dedicou às Artes Industriais e à Educação Artística. Naquela data ela contaria pouco mais de 20 anos de idade.
} 
trabalhos manuais na escola. O livro, publicado pela Imprensa Oficial de Minas Gerais em 1934, é uma brochura com 171 páginas, fartamente ilustrado, "com 402 desenhos no têsto (sic!), sendo 30 dos quais coloridos e em páginas intercaladas". O autor destacava a sua capa como um exemplo de trabalhos manuais, pois era uma "brochura de recorte a tesoura em papel”, com destaque à imagem das mãos segurando um formão e um martelo.

FIGURA 1- Capa do livro de Manoel Penna.

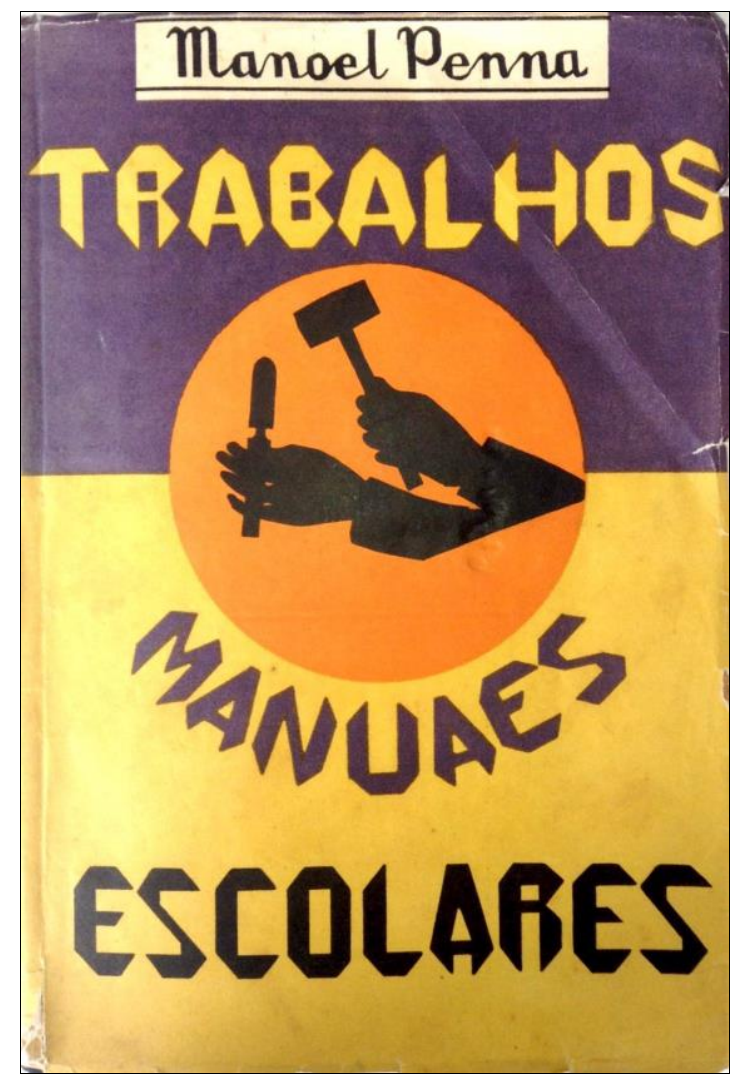

Fonte: Acervo pessoal da professora Carla Simone Chamon (Cefet/MG).

Na página dedicada ao Prefácio, Penna afirma que o livro "é fruto de longos anos de prática como professor de trabalhos manuais, estudando e experimentando o que os mestres ensinam". Em seguida arrola os autores aos quais recorreu para a escrita do seu compêndio: "Omer Buyse, G. Kerchensteiner, J. Montua, Dewey, E. Solana, Manael Frazão, Daujat et Dumont, P. Martin, M. Montessori, Froebel, F. Blanch e outros”.

O livro está organizado a partir de uma Introdução geral, na qual o autor percorre diferentes perspectivas para pensar os trabalhos manuais, valendo-se de exemplos de outros países e de autores variados. Em seguida, um tópico denominado Varios Sistemas apresenta vantagens e desvantagens de diferentes concepções, sendo que o autor assume alguma predileção pelas concepções do Sloyd sueco e da escola de trabalho de Georg Kerchensteiner, expressão última da "escola nova ou escola ativa" (Penna, 1934, p. 16). ${ }^{12}$ Na sequência, em um tópico denominado $D a$ necessidade do ensino de trabalhos manuais, o autor apresentará o conjunto de argumentos a favor do seu desenvolvimento, destacando as suas finalidades em um processo de formação geral. Segue-se um tópico chamado A orientação moderna no ensino dos trabalhos manuais, no qual o autor discorre sobre o tripé "sensibilidade, atividade e inteligência", com destaque ao "aprender

${ }^{12}$ Os Trabalhos Manuais na escola já foram objeto do estudo de Pinheiro e Munakata (2017), que mostram como os mesmos, a despeito da sua propalada importância para todos, ganhavam significados diversos segundo a posição social e econômica dos alunos aos quais se destinava. 
fazendo" (p. 22). A partir daí o livro percorre as diferentes expressões dos trabalhos manuais escolares tendo o desenho como fundamento de todos eles: trabalhos em papel (dobramentos), tecidos, cartonagem e colagem, modelagem e trabalhos em madeira, nessa ordem. Para cada uma das seções o autor propõe a sequência Plano, Materiais, Primeiros Exercícios, seguida de uma profusão de exercícios a serem desenvolvidos nas escolas, 153 no total. A essa sequência se seguem comentários sobre os efeitos daqueles exercícios na formação dos alunos, na medida em que os trabalhos manuais contribuem para o atingimento dos objetivos de todas as demais disciplinas escolares, sendo a base de um amplo processo de formação geral.

Percorrendo as ponderações de Penna, destacamos o conjunto de finalidades que o autor vai gradativamente definindo para o ensino dos trabalhos manuais nas escolas. Reconhecendo o "atraso do nosso povo" em relação à sua importância, o autor realça o seu caráter de meio educativo no ensino primário e secundário. Nesse sentido, nas páginas iniciais do seu texto os Trabalhos Manuais são considerados como uma disciplina escolar específica, a dar suporte a todas as demais disciplinas. Ela não se ocuparia de uma formação especializada "por ser humanamente impossível e constituir mesmo um grande absurdo" imaginar que com ela se aprenderiam ofícios e se formariam "verdadeiros profissionais" (Penna, 1934, p. 10). Os Trabalhos Manuais educativos nesse sentido se distinguiriam radicalmente do ensino profissional propriamente dito, para os quais deveria ser estimulada a criação de estabelecimentos próprios para formar o "operário moderno". Lembra que pelo simples reconhecimento da nossa tradição escravista, e pelo preconceito que grassava contra o trabalho manual e os operários, só por isso já valeria à pena aquele ensino nas escolas, uma vez que ali se poderiam formar "ideias de igualdade e fraternidade próprias dos ideais democráticos e republicanos". Em um momento de forte cerceamento das tradições dos imigrantes estrangeiros no país, é sintomático que o autor alegasse que os jovens brasileiros pobres estavam em desvantagem em relação aos "competidores estrangeiros" (p.11). Assim, Penna mesclava argumentos gerais de caráter pedagógico-formativo invocando uma "educação completa" que passava pela educação física e "especialmente a educação dos sentidos", com argumentos pragmáticos que remetiam ao lugar que deveria ser ocupado pelos alunos no mundo do trabalho, do qual a escola não poderia descurar. Para ele o tato era o sentido por excelência para desenvolver o senso de atividade, ação, dos alunos, e lembrava que o Sloyd estava enraizado no vocábulo slog, que significava hábil, destro. Lembrando que o mundo "impressiona os nossos sentidos", o seu pleno desenvolvimento representaria importante "medida da moral" desejada para as novas gerações (p. 31), tal como destacavam as professoras que escreviam em A Escola, do Paraná, ou os autores que publicavam na Revista do Ensino, em Minas.

Ao tratar, por exemplo, do desenho como fundamento dos trabalhos manuais, ele já reconhecia que aquela prática era, per si, um tipo de trabalho das mãos de grande apelo estético:

O desenho se recomenda no ensino como um dos melhores, talvez o melhor meio de atividade para o desenvolvimento e educação da sensibilidade moral da criança, principalmente pelo lado referente ao prazer, ao gosto, despertando nela os sentimentos do Belo, do Justo, tornando suas almas mais sensíveis pelos exercícios contínuos e exame minucioso das cousas da natureza, em observações e meticulosos estudos (Penna, 1934, p. 24).

Denominando o seu sistema de educativo-instrutivo, por combinar as contribuições de Decroly e Kerchensteiner com os "méritos incontestáveis do sloyd, no 
que êste possue de mais educativo", Penna arrolava o conjunto de potencialidades das suas proposições.

...inspirar nas crianças o amor ao trabalho, mormente ao mais rude; dar-lhes hábitos de ordem, asseio, elegância e exatidão; educar-lhes a vista, dando-lhes também dextreza (sic!) de mãos; desenvolver-lhes a independência e a confiança, acostumando-as igualmente a perseverança, aproveitar-se-á nelas a atividade natural nas suas três formas - instinto, vontade e hábito, atividade esta que constitue a base da vida humana, para desenvolvendo-a, ir-se desde logo, por meio do trabalho das mãos, numa associação lógica e inteligente, iniciando o ensino de outras matérias do programa, como leitura, escrita, história, geografia, geometria, aritmética, história natural, física etc... (1934, p. 25).

Rematava:

Organizados cuidadosamente e obedecendo às dificuldades crescentes do ensino, estas lições, constituídas por um entrelaçamento sutil do ensino manual com o intelectual, visam, como ficou dito, o desenvolvimento paralelo e integral de todas as faculdades infantis, por meio de ações conscientes dos sentidos, porque somente por meio dessas, que têm origem nas células motoras do cérebro, é que há enriquecimento de imaginação, elaboração do pensamento, desenvolvimento da vontade, etc. (Penna, 1934, p. 26).

Essa ênfase moral, que vinha recoberta de preocupações de caráter cívico, o que aumentava o rol de finalidades atribuídas aos trabalhos manuais, é evidenciada quando Penna discorre sobre o resultado dos trabalhos com modelagem com argila ou cera. Seguindo minuciosamente as orientações oferecidas pelo seu livro, os professores chegariam à produção de peças que retratariam "grandes nomes" ou episódios da história do país, listando a importância de personagens como "Deodoro, Santos Dumont, Oswaldo Cruz, Pedro Américo, Carlos Gomes" (p. 148). Mas também a geografia e a fauna brasileiras poderiam ser representadas, o que evidenciava o caráter fundamental daqueles trabalhos como suporte das mais diversas disciplinas. 
FIGURA 2 - Lição de trabalhos com argila e cera

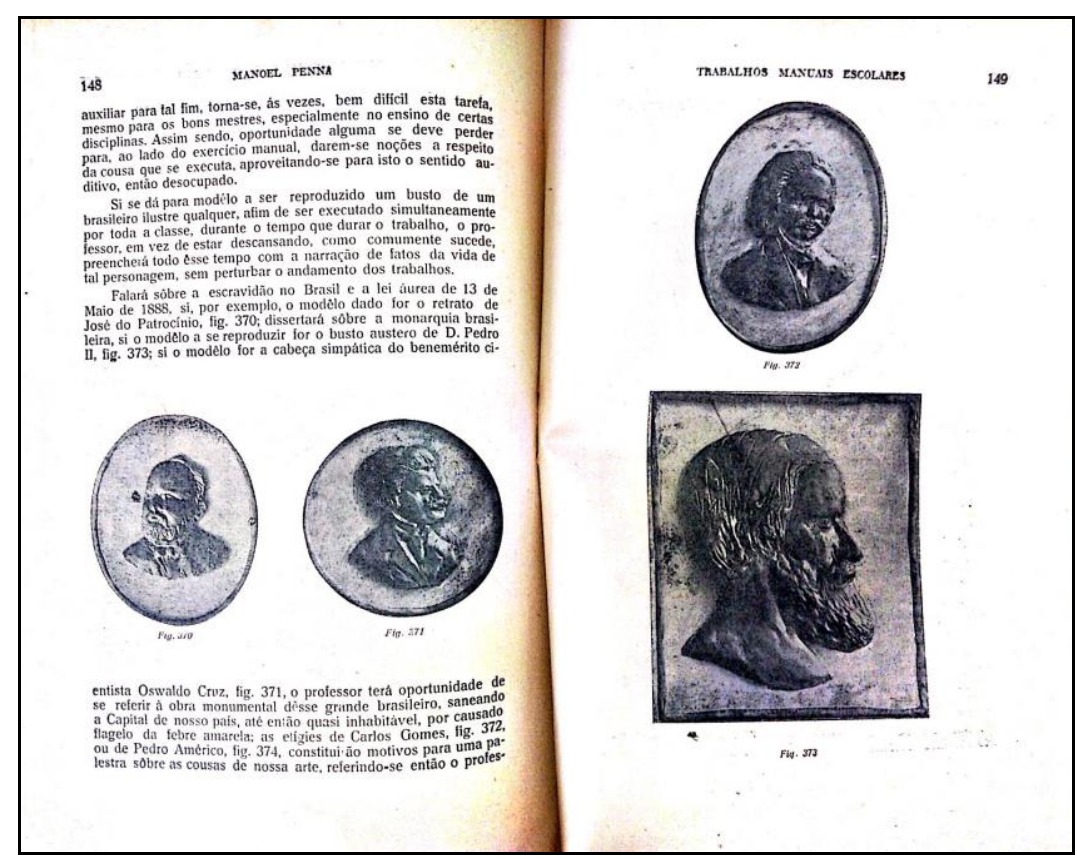

Fonte: Penna (1934, p.372-3)

Já, ao discorrer sobre os trabalhos com madeira o autor lembrava que, diferentemente da ginástica calistênica ou sueca, tão difundidas, sem qualquer finalidade que fosse além da simples exercitação corporal, eles representavam um tipo de "ginástica natural", "utilitária e produtiva", caracterizando um importante vetor da formação geral.

O livro percorria um longo caminho que iniciava com prescrições e exercícios para o ensino do desenho, chegando à complexidade dos trabalhos com madeira. Apresentava formas de empunhadura e manutenção de materiais básicos, até o treinamento das habilidades necessárias para operar com ferramental complexo.

FIGURA 3: Exercícios elementares de desenho.

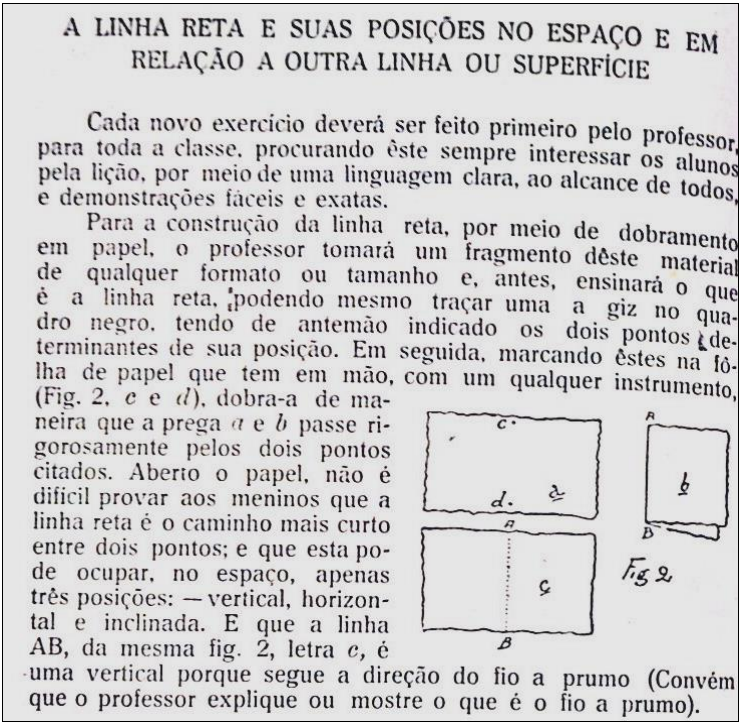

Fonte: Penna (1934, p. 34) 
Em seguida, dos primeiros desenhos os professores eram estimulados a ensinar a sua aplicação prática, inclusive em relação a outras habilidades requeridas dos alunos.

FIGURA 4 - Exemplos de como as aulas de desenho poderiam ajudar na alfabetização dos alunos.

Feitas as letras obedecendo-se em tudo ao modêlo dado, deverão as mesmas ser pregadas no papel quadriculado, com toda a exatidão possivel, tal qual se về na referida figura.

\section{FXERCiCIO $N$. 2}

Formar, pela mesma maneira, o grupo VL (fig. 39).

Sempre que a tira tenha de traçar um angulo reto, a dobra da mesma deverá ser pela diagonal do quadrado; mas, para angulos de outros graus, a prega varia, como acontece na execução da letra $V$ dèsse conjunto.

No mais se procede como se fez no primeiro dêstes exercicios.

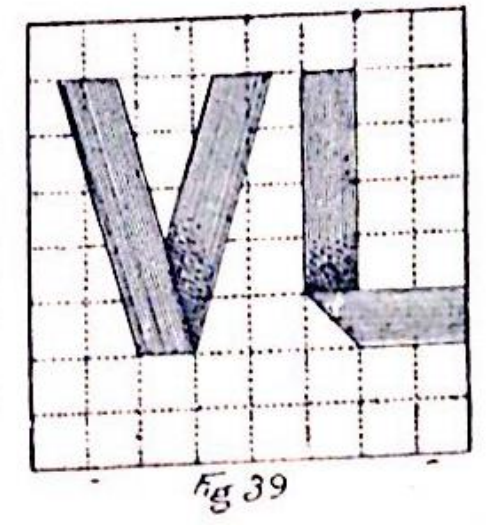

EXERCicio $\mathrm{x} .3$

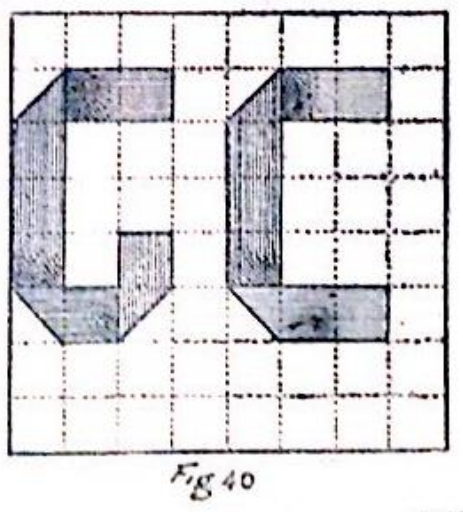

Extereforo $N .4$ 41).

Composição das letras $\mathrm{AN}$ (fig. Há algumas letras, como o A,
por exemplo, cujas dobras ficam ocultas por detris, parecendo que sĩo feitas em pedaços, o que na realidade não acontece.
Compor o grupo das consoantes - G e C.

Proceder-se-a pela mesma for: ma que nos anteriores exercicios; adverte-se, porem, que as dobras devem ser alternadas, como se nota nestas duas da fig. :40. Ora para um lado, ora para o outro.

Fonte: Penna (1934, p.47). 
FIGURA 5: Exercícios de dobramento e colagem.

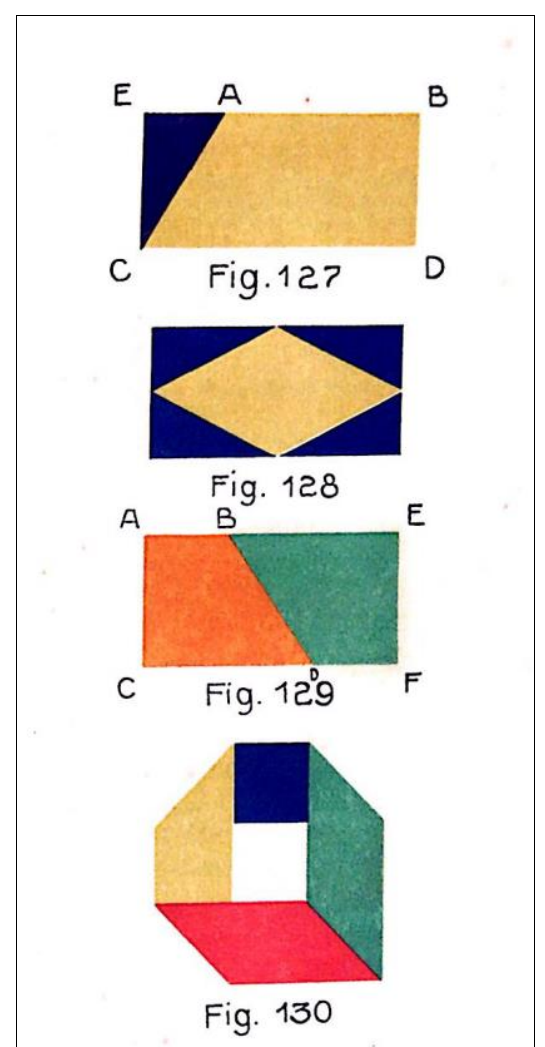

Fonte: Penna (1934, s.p.)

A progressão era concluída com os exercícios de modelagem em argila e cera, além da discussão de elaboração de peças em madeira, sendo que este último material recebeu relativa pouca atenção do autor se comparado com os outros.

FIGURA 6: Exercício para a construção de um cilindro.

\section{EXEIBCICIO $N, 1.48$}

Construção de um cilindro, fig. 353 - A.

\section{Desenho.}

Toma-se uma porção de argila, maior um pouco do que a com que se produziu a esfera, e, com as pontas dos dedos, vaise-the dando a forma redonda que se nota na citada fig. Depois disto, com as extremidades dos dedos e sôbre uma superfipie plani qualquer, rola-se a massa de leve ate que esta adquira a conformação cilindrica, com as bases bem paralelas, como se vè na letra $A$ da referida fig. 353.

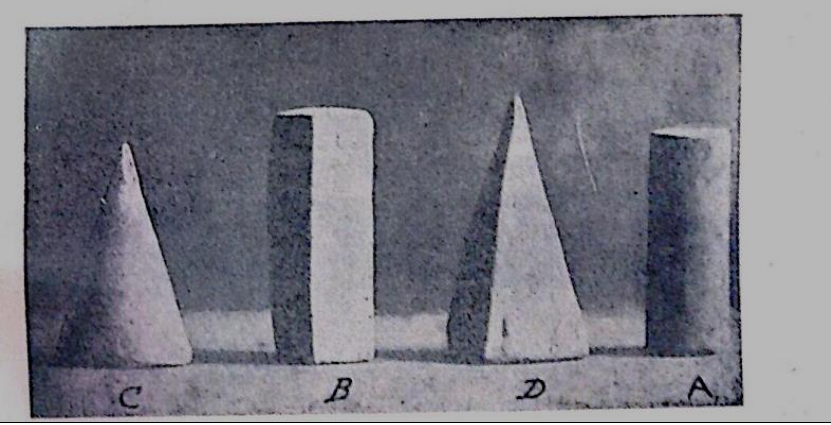

Fonte: Penna (1934, p. 137). 
A centralidade dos Trabalhos Manuais no período aqui sugerido repousava não apenas no fato de servir como elemento nucleador de outras disciplinas, mas também porque fundamentava o apelo por uma educação escolar pública reivindicada como moderna, que tinha a ação, a atividade, a iniciativa, a autonomia como pressupostos básicos, em oposição à tradicional educação considerada beletrista, mnemônica e passiva. Pelo menos em discurso, se pretendia superar os modelos pedagógicos do passado dotando os alunos de aptidões para o enfrentamento dos desafios do mundo novo que se descortinava. Mas como mostra o minucioso manual de Manoel Penna, não apenas de discurso se tratava. Não se pretendia, em princípio, formar artífices ou operários, mas uma sensibilidade adequada ao mundo urbano industrial que se afirmava. Essa sensibilidade pressupunha o conhecimento do próprio corpo, a cuidadosa educação dos sentidos, a ênfase na educação da vontade e na capacidade de tomar decisões dos alunos. Esses preceitos, se faziam parte do que pode ser conhecida como uma agenda liberal para a organização da cultura, não eram estranhos às formulações de educadores socialistas ou anarquistas naquelas décadas iniciais do século XX. Logo, o desenvolvimento de um ethos do trabalho parecia não acompanhar, como bem mostra a reivindicação pelo direito ao trabalho denunciada por Paul Lafargue em 1882 (1990), a noção do trabalho como danação, o que o autor chamaria de um dogma desastroso. Antes, pelo menos nessa dispersão discursiva da qual as duas revistas aqui consideradas são apenas uma mostra, as décadas iniciais do século XX parecem ter sido anos de crença na passagem para um mundo que libertaria os homens dos grilhões do trabalho servil, conforme exaltava Penna em seu livro. Logo, os Trabalhos Manuais cumpriam um papel chave na afirmação daquele ethos mostrando que a plena realização do mundo novo dependeria da contribuição de todos e de cada um, através do suor do seu rosto e a habilidade das suas mãos. A maldição do trabalho escravo, ou mesmo considerações sobre a alienação pelo trabalho, marcas da sociedade brasileira, não eram mencionadas nas revistas mobilizadas, pois o trabalho era positivado e se afirmava como capaz de redimir os homens da dependência do puro estado de natureza, concorrendo para a sua humanização, a qual dependia da sua ação efetiva sobre a mundo. Tratava-se, seguindo a crítica de Lafargue (1990) das bênçãos do trabalho. Mas Manoel Penna iniciava o seu livro denunciando um suporto atraso brasileiro em relação a outros países, uma vez que aqui o trabalho continuava sendo objeto de desprezo. Só por isso, segundo o autor, já deveria ser estimulado nas escolas.

É justamente nesse sentido que noções como economia moral, conforme desenvolvida por Edward Thompson (1998) e vida ativa, explora por Hannah Arendt (1958[2014]), se tornam importantes para contrapor leituras reducionistas que tomam o trabalho apenas na sua negatividade. Afinal, se como observou Marx o trabalho é o "metabolismo do homem com a natureza", preocupar-se com o desenvolvimento de um ethos do trabalho pela via escolar parece ser o reconhecimento que também pelo trabalho o homem se humaniza. A questão a ser atualizada é sempre de indagar quando e como o trabalho assumiu, na história, uma dimensão "positiva" ou "negativa" no que se refere às práticas educativas, talvez ao modo como ensaiaram Pinheiro e Munakata (2017).

\section{REFERÊNCIAS}

ALMEIDA GONZAGA, Albrigio. Finalidade do trabalho manual para mulheres. Minas Gerais: Revista do Ensino, n ${ }^{\circ}$, 1925, pp. 117-123. 
Ensino profissional: o civismo e o trabalho manual. Minas Gerais: Revista do Ensino. $\mathrm{n}^{\circ}$ 7, 1925, pp. 182-184.

ARAÚJO, Silvete Aparecida Crippa de. Professora Julia Wanderley: uma mulher-mito (1874-1918). Curitiba: Editora UFPR, 2013.

ARENDT, Hannah. Trabalho, obra, ação. Cadernos de Ética e Filosofia Política. São Paulo, 7, 2/2005, pp. 175-201.

A condição humana. Rio de Janeiro: Forense, 2014.

BRAGHINI, Katya; MUNAKATA, Kazumi; TABORDA DE OLIVEIRA, Marcus Aurelio. Diálogos sobre a educação dos sentidos e das sensibilidades. Curitiba: Editora UFPR, 2016 (no prelo).

CARUSO, Marcelo. La biopolítica en las aulas: prácticas de conducción en las escuelas elementares del Reino de Baviera, Alemaña (1869-1919). Buenos Aires: Prometeo Libros, 2005. https://doi.org/10.1590/s0102-46982007000200017

GOES, Carlos. Ensino primário profissional. Minas Gerais: Revista do Ensino, n. 1, 1925, p. 4-5.

LAFARGUE, Paul. O direito à preguiça e outros textos. São Paulo: Edições Mandacaru, 1990.

LEÃO, Ermelino de. Pedagogia. Curitiba: A Escola, n. 2, 1906, pp. 72-77.

LESSA, Gustavo. Orientação da escola ativa nos Estados Unidos. Minas Gerais: Revista do Ensino, n. 38, 1929, pp. 52-73.

MENDONÇA, Anna Amelia de Queiroz. Canto do trabalho. Minas Gerais: Revista do Ensino, no 11, 1926, p. 52.

MOREAU, Alicia. A pedagogia e a escola. Curitiba. A Escola. n. 9-10, 1906, pp. 155-161.

PEREIRA, Ester. Curso de Pedagogia. Curitiba: A Escola, n. 7, 1906, pp. 122-126.

PETRICH, Julia Wanderley. Relatórios. Curitiba: A Escola, n. 1, 1906, pp. 17-25.

PINHEIRO, Tainã; MUNAKATA, Kazumi. Os trabalhos manuais na escola republicana. In: BRAGHINI, Katya; MUNAKATA, Kazumi; TABORDA DE OLIVEIRA, Marcus Aurelio (orgs). Diálogos sobre a educação dos sentidos e das sensibilidades. Curitiba: Editora UFPR, 2017.

PUCHTA, Diogo. A escolarização dos exercícios físicos e os manuais de Ginástica no processo de constituição da Educação Física como disciplina escolar (1882-1926). Programa de Pós-Graduação em Educação e Inclusão Social. UFMG, Belo Horizonte, 2015. https://doi.org/10.19177/prppge.v9e162015384-398

RANGEL, José. O ensino profissional. Minas Gerais: Revista do Ensino, 1927, n. 23, pp. 523-524. 
ROCHA, Marlos Bessa Mendes. Matrizes da modernidade republicana: cultura política e pensamento educacional no Brasil. Campinas: Autores Associados, 2004. https://doi.org/10.1590/s1413-24782004000300016

SANTOS, Lucio José dos. Educação utilitária. Minas Gerais: Revista do Ensino, n ${ }^{\circ}$, 1925, pp. 81-82.

SOUZA, Rosa Fátima de. Templos de civilização. São Paulo: Unesp, 1998.

Inovação educacional no século XIX: a construção do currículo da escola primária no Brasil.

Caderno CEDES, Campinas, n. 52. 2000. https://doi.org/10.1590/s0101-32622000000200002

SOUZA, Rosa Fatima de et al (orgs). Escola primária na Primeira República (1889-1930): subsídios para uma história comparada. Araraquara, SP: Junqueira \& Marin, 2012.

TABORDA DE OLIVEIRA, Marcus Aurelio. Sentidos e sensibilidades: sua educação na história. Curitiba: Editora UFPR, 2012.

O lugar do intelectual no prelúdio da modernidade: experiência e tradição seletiva na obra de José Francisco da Rocha Pombo. In: VALLE, Ione, HANDAN, Juliana e DAROS, Maria das Dores (Orgs.). Moderno, modernidade e modernização: a educação nos projetos de Brasil - séculos XIX e XX (Vol. 2). Belo Horizonte: Mazza Edições, 2014. https://doi.org/10.5965/1984723815282014412

Educação da vontade e renovação pedagógica nos contextos espanhol e brasileiro, nas décadas iniciais do século XX. Belo Horizonte: UFMG, 2017. (Texto inédito). https://doi.org/10.1590/s1413-24782019240008

THOMPSON, Edward. William Morris: de romântico a revolucionário. Valencia: Alfons el Magnanim, 1976.

Costumes em comum. São Paulo: Companhia das Letras, 1998. https://doi.org/10.1590/s0104-71831999000100015 